Check for updates

Cite this: RSC Adv., 2017, 7, 54017

Received 28th October 2017

Accepted 20th November 2017

DOI: $10.1039 / c 7 r a 11875 a$

rsc.li/rsc-advances

\section{Synthesis of $\alpha$-sulfonyloxyketones via iodobenzene diacetate (PIDA)-mediated oxysulfonyloxylation of alkynes with sulfonic acids $\uparrow$}

\begin{abstract}
Yang Zhang, * Hua Tan and Weibing Liu (D) *
A simple yet powerful method to synthesize a variety of $\alpha$-sulfonyloxyketones has been developed. This novel method can be applied for the direct oxysulfonyloxylation of alkynes with sulfonic acids to access a variety of $\alpha$-sulfonyloxyketones. Compared to the reported methods for the application of PIDA, this study expands its application scope and uses it not only as the oxidant but also as the carrier of "O" to form the carbonyl group in the products. In addition, under the established conditions, this methodology not only exhibits a broad substrate scope but also demonstrates exclusive regioselectivity with substrates of 1,2-disubstituted internal alkynes.
\end{abstract}

In recent decades, due to their low toxicity, high stability, environmental-friendliness, easy availability, clean transformation and very useful oxidizing properties, hypervalent iodine compounds have attracted great interest from the chemical synthesis community ${ }^{1}$ and emerged as a useful alternative for a wide variety of organic transformations. ${ }^{2}$ To date, the existing studies have mainly focused on the oxidation reactions which use iodine(III) and iodine(v) compounds as substitutes to replace highly toxic heavy-metal-based oxidants. ${ }^{3}$ Recently, the application scope of hypervalent iodine reagents has been expanded, and a dual role has emerged for iodine(III) and iodine(v) compounds in organic oxidation transformations which employ them not only as organic oxidants, but also as carriers of some organic functional groups, such as $-\mathrm{O}_{2} \mathrm{CR},{ }^{4}$ $-\mathrm{CF}_{3},{ }^{5}-\mathrm{OTs},{ }^{6}-\mathrm{NR}_{2},{ }^{7}-\mathrm{C} \equiv \mathrm{C}-\mathrm{R},{ }^{8}-\mathrm{N}_{3},{ }^{9}$ and $-\mathrm{Ar}^{10}{ }^{10}$ in the "atomtransfer" oxidative coupling reactions that lead to the formation of new $\mathrm{C}-\mathrm{C}$ and $\mathrm{C}-$ hetero bonds. However, reports involving the use of hypervalent iodine reagents as the "O" source of a carbonyl group are very rare to date. Since our protracted interest in the community of hypervalent iodine reagents involves oxidative reactions, ${ }^{11}$ in this report we will describe one such process using PIDA as the oxidant and the "O" source for carbonyl group, along with alkynes and sulfonic acids to access $\alpha$-sulfonyloxyketones in a one-step procedure (Scheme 1). $\alpha$-Sulfonyloxyketones are important organic intermediates ${ }^{12}$ for $\alpha$-azidation of ketones ${ }^{13}$ and the synthesis of a variety of heterocyclic compounds. ${ }^{14}$ To date, a variety of synthetic approaches have been reported for their synthesis, however,

College of Chemical Engineering, Guangdong University of Petrochemical Technology, 2 Guandu Road, Maoming 52500o, P. R. China. E-mail: 450692624@qq.com; lwb409@gdupt.edu.cn; Fax: +86-668-2923575; Tel: +86-668-2923956

$\dagger$ Electronic supplementary information (ESI) available. See DOI: $10.1039 / \mathrm{c} 7 \mathrm{ra} 11875 \mathrm{a}$ they have mainly been focused on the oxidative transformations between ketones and sulfonic acids. ${ }^{15}$ The present study describes the synthesis of $\alpha$-sulfonyloxyketones via direct difunctionalization of alkynes with sulfonic acids in the presence of PIDA to produce $\alpha$-sulfonyloxyketones, which is an approach that to the best of our knowledge has not been reported until now.

This study was started by using the model substrates phenylacetylene (1a) and $p$-toluenesulfonic acid (PTSA) (2a) to probe the feasibility of this reaction (Table 1). Initially, the reaction was performed with 1 equiv. of PIDA in 1,2-dichloroethane (DCE) at room temperature for 12,24 and $36 \mathrm{~h}$. We were satisfied to find that the desired product 1-oxo-1-phenylethyl 4-methylbenzenesulfonate 3aa, was obtained with a $39 \%, 54 \%$ and $54 \%$ yield, respectively (entries 1-3). These moderate yields motivated us to improve the yield of the desired product 3aa. On switching from DCE to other solvents like toluene, dioxane, $\mathrm{CH}_{3} \mathrm{CN}, \mathrm{CH}_{3} \mathrm{OH}$ and $\mathrm{Et}_{3} \mathrm{~N}$ (entries 4-8), the best result was obtained in $\mathrm{CH}_{3} \mathrm{CN}$ (80\% yield) (entry 6). Intriguingly, the reaction performed poorly when the reaction was carried out at $70{ }^{\circ} \mathrm{C}$, and the yield of the product 3aa decreased to $57 \%$ (entry 9). In contrast, a slight increase in the yield was obtained by varying the equivalents of PIDA from 1.0 to 1.3 (entry 10).

The scope of the reaction was investigated by varying the substrates of $\mathbf{1}$ and $\mathbf{2}$ under the established conditions (Scheme 2). Initially, the reaction of a variety of terminal arylethynylenes bearing various substituents was investigated first.

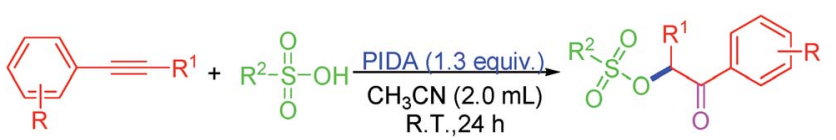

Scheme 1 PIDA-mediated oxysulfonyloxylation of alkynes. 
Table 1 Optimization of the reaction conditions ${ }^{a}$

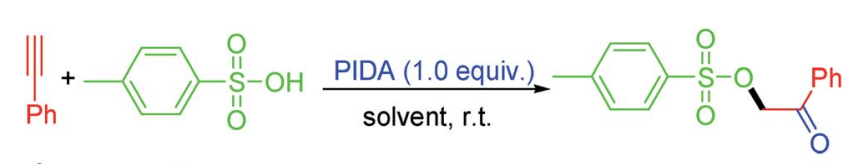

$1 a \quad 2 a$

3aa

\begin{tabular}{llll}
\hline Entry & Solvent & Time $(\mathrm{h})$ & Yield $^{b}$ \\
\hline 1 & DCE & 12 & 39 \\
2 & DCE & 24 & 54 \\
3 & DCE & 36 & 54 \\
4 & Toluene & 24 & 61 \\
5 & Dioxane & 24 & 75 \\
6 & $\mathrm{CH}_{3} \mathrm{CN}$ & 24 & 80 \\
7 & $\mathrm{CH}_{3} \mathrm{OH}$ & 24 & 21 \\
8 & $\mathrm{Et}_{3} \mathrm{~N}$ & 24 & 27 \\
$9^{c}$ & $\mathrm{CH}_{3} \mathrm{CN}$ & 24 & 57 \\
$10^{d}$ & $\mathrm{CH}_{3} \mathrm{CN}$ & 24 & 85
\end{tabular}

${ }^{a}$ Reaction conditions: $\mathbf{1 a}(1.0 \mathrm{mmol}), \mathbf{2 a}(1.0 \mathrm{mmol})$, PIDA (1.0 equiv.), solvent $(2.0 \mathrm{~mL}) .{ }^{b} \mathrm{GC}$ yield. ${ }^{c}$ Reaction temperature: $0{ }^{\circ} \mathrm{C} .{ }^{d}$ PIDA: 1.3 equivalent.

It was found that the electronic properties of the substituents on the phenyl ring did not affect the yield too much. According to the results of the yields, terminal arylethynylenes bearing electron-donating substituents (i.e., alkyl and methoxy) performed slightly better in this transformation than those bearing electron-withdrawing substituents (i.e., $\mathrm{F}^{-}, \mathrm{Br}^{-}$and $\mathrm{Cl}^{-}$), and produced the desired product in relatively high yields. For instance, terminal arylethynylenes bearing electron-donating substituents, such as Me (1) $)$, Et (1d), propyl (1e), ${ }^{t} \mathrm{Bu}(\mathbf{1 f})$ and $\mathrm{MeO}(\mathbf{1} \mathbf{j})$ produced the desired products $\mathbf{3} \mathbf{b a}, \mathbf{3 d a}, \mathbf{3 e a}, \mathbf{3} \mathbf{f a}$ and 3ja in good yields, while electron-withdrawing substituents, such as the $\mathrm{F}(\mathbf{1 g})$ and $\mathrm{Cl}(\mathbf{1 h})$ groups led to decreased yields. Also, we were disappointed to find that the position of a given substituent on the phenyl ring of terminal arylethynylenes did impact the yield significantly, and para-substituted products were more favorable than ortho- and meta-substituted ones. For example, 1-bromo-2-ethynylbenzene (1i) produced 3ia with the lowest yield (59\%). To our satisfaction, this conversion proceeded smoothly with high regioselectivity when 1,2-disubstituted internal alkynes like methyl 3-phenylpropiolate (1k) and 1-(pent-1-ynyl)benzene (11) were used as the substrates and produced their corresponding product (3ka and 3la) with excellent yield. In order to further expand the scope of this protocol, several sulfonic acid derivatives like methanesulfonic acid (2b), ethanesulfonic acid (2c), phenylsulfonic acid (2d) and naphthalene sulfonic acid (2e) were used as substrates under the established conditions. The experimental results confirmed that all these aliphatic sulfonic acids and arylsulfonic acids are excellent partner of PTSA (2a), and all the tested reactions proceeded smoothly and produced their corresponding product with excellent yield (3ab: $87 \%$, 3ac: $85 \%$, 3ad: $82 \%$ and 3ae: $81 \%)$.

To clarify the source of oxygen in the generated carbonyl group in this work, we conducted two control experiments

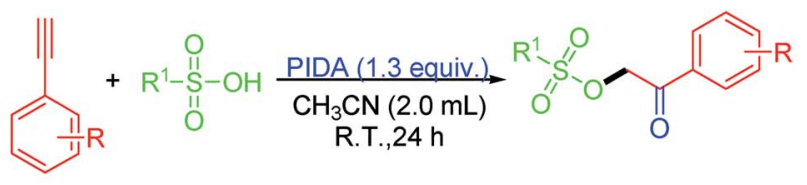

1

2 3

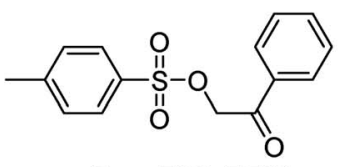

3aa $79 \%(77 \%)$<smiles>Cc1ccc(C(=O)COS(=O)(=O)c2ccc(C)cc2)cc1</smiles><smiles>Cc1ccc(S(=O)(=O)OCC(=O)c2cccc(C)c2)cc1</smiles>

3ca $73 \%$<smiles>CCc1ccc(C(=O)COS(=O)(=O)c2ccc(C)cc2)cc1</smiles>

3da $80 \%$<smiles>CCCc1ccc(C(=O)COS(=O)(=O)c2ccc(C)cc2)cc1</smiles>

3ea $84 \%$

3fa $81 \%$<smiles>Cc1ccc(S(=O)(=O)OCC(=O)c2ccc(F)cc2)cc1</smiles><smiles>Cc1ccc(S(=O)(=O)OCC(=O)c2ccc(Cl)cc2)cc1</smiles><smiles>Cc1ccc(S(=O)(=O)OCC(=O)c2ccccc2Br)cc1</smiles><smiles>COc1ccc(C(=O)COS(=O)(=O)c2ccc(C)cc2)cc1</smiles>

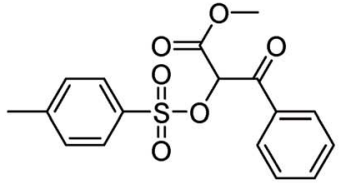

3ka $85 \%$<smiles>CS(=O)(=O)OCC(=O)c1ccccc1</smiles>

3ab $87 \%$

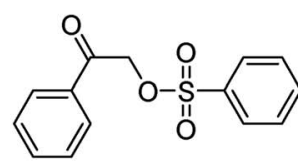

3ad $82 \%$<smiles>CCCC(OS(=O)(=O)c1ccc(C)cc1)C(=O)c1ccccc1</smiles>

3la $83 \%$<smiles>CCS(=O)(=O)OCC(=O)c1ccccc1</smiles>

3ac $85 \%$

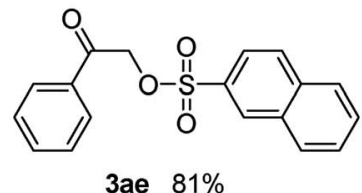

Scheme 2 Exploring of the substrate scope (all reactions are carried out on a $2.0 \mathrm{mmol}$ scale using $\mathrm{CH}_{3} \mathrm{CN}(2.0 \mathrm{~mL})$ as the solvent and all the listed yields are isolated yield. The number in parentheses is the isolated yield of propiophenone $1 \mathrm{a}(10.0 \mathrm{mmol}$ scale) after purification by column chromatography). 


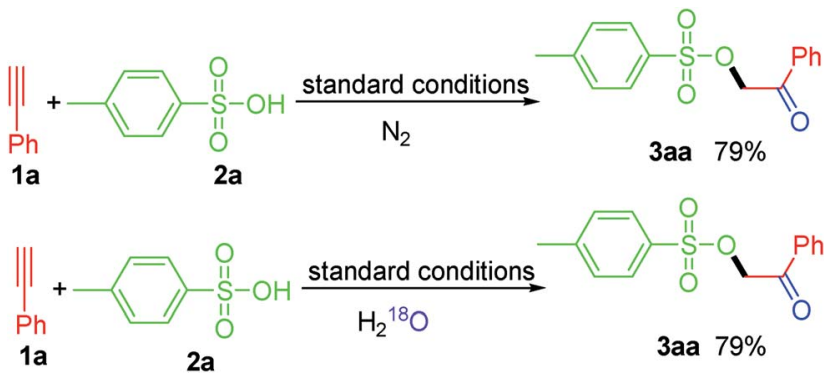

Scheme 3 Control experiments.

(Scheme 3). Firstly, we noticed that the yield of 3aa was not affected when the reaction was conducted under nitrogen atmospheres, which ruling out the possibility of the involvement of atmospheric oxygen for this transformation. Besides, when the reaction was carried out in the presence of excess $\mathrm{H}_{2}{ }^{18} \mathrm{O}$, 3aa was obtained with a $79 \%$ yield without ${ }^{18} \mathrm{O}$-labeled in the product, thereby excluding the possibility of the "O" being derived from $\mathrm{H}_{2} \mathrm{O}$ in the reaction system. Taken together, we believe that the "O" in the carbonyl group in this work is derived from PIDA.

Based on the results of the experiments described above, a plausible mechanism is proposed, as shown in Scheme 4 and exemplified by the production of 3aa. The reaction begins with the formation of bridged iodonium ion $\mathbf{4}$ through the activation of 1a by $\mathrm{PhI}(\mathrm{OAc})_{2}$ together with the spontaneous dissociation of the acetoxy anion from the iodine center. ${ }^{7}$ The second step involves the direct nucleophilic oxysulfonyloxylation of $\mathbf{4}$ and yields intermediate 5. Subsequently, the reduction elimination of 5 through the release of $\mathrm{PhI}$ leads to the formation of intermediate 6 which undergoes hydrolysis to produce the enol 7.16 Finally, the tautomerization of enol 8 liberates the stable $\alpha$ sulfonyloxyketone 3aa. Alternatively, the reaction maybe begins with the combination of 1a with PIDA to activate the C-C triple bond to give electrophilic intermediate 8 , which then reacts with the nucleophilic acetate anion to generate intermediate 9. ${ }^{17}$ The release of one molecule of acetate anion from intermediate 9 yields iodonium ylide 10. The following hydrolysis of

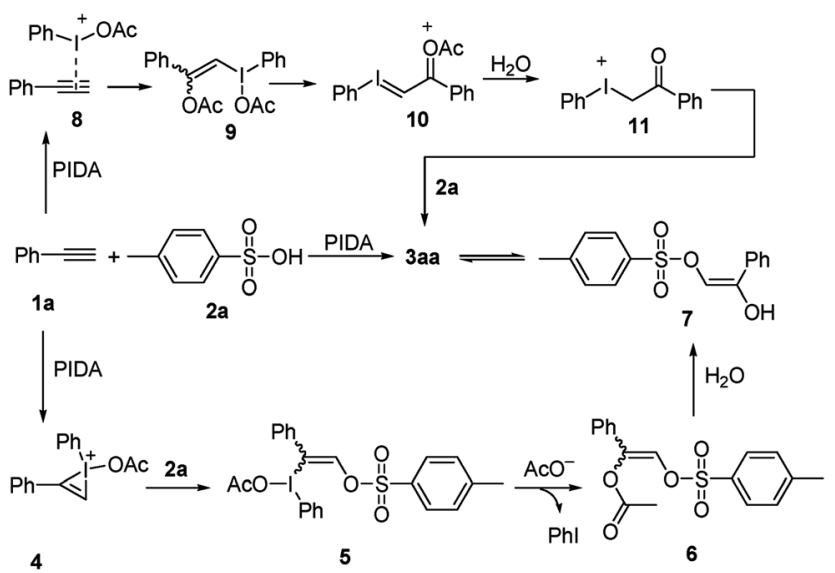

Scheme 4 Possible reaction mechanism. the ylide 10 gives ketone intermediate $11 .{ }^{18}$ Then the nucleophilic attack of sulphonate anion on the electrophilic iodonium cation affords the final product $\alpha$-sulfonyloxyketone 3aa.

In conclusion, we have developed a novel hypervalent iodine(III)-promoted method for oxysulfonyloxylation of alkynes using sulfonic acids to access $\alpha$-sulfonyloxyketones. Compared to the reported methods involving the application of PIDA, the present study expands the application scope of PIDA as an oxidant and O-source of carbonyl group. In general, this approach exhibited a broad substrate scope for the synthesis of $\alpha$-sulfonyloxyketones under milder conditions. In addition, the easy availability of reactants as well as the use of simple oxidant and O-source makes the present method a useful new option for $\alpha$-sulfonyloxyketone synthesis.

\section{Conflicts of interest}

There are no conflicts to declare.

\section{Notes and references}

1 A. Nakamura, S. Tanaka, A. Imamiya, R. Takane, C. Ohta, K. Fujimura, T. Maegawa and Y. Miki, Org. Biomol. Chem., 2017, 15, 6702; R. Sakamoto, T. Inada, S. Selvakumar, S. A. Moteki and K. Maruoka, Chem. Commun., 2016, 52, 3758.

2 E. Deruer and S. Canesi, Org. Biomol. Chem., 2017, 15, 3736.

3 C. Yang, G. Y. Cheng, B. F. Huang, F. T. Xue and C. Jiang, RSC Adv., 2016, 6, 87134; G. X. Li, C. A. Morales-Rivera, Y. X. Wang, F. Gao, G. He, P. Liu and G. Chen, Chem. Sci., 2016, 7, 6407.

4 Z. J. Wang, M. Kanai and Y. Kuninobu, Org. Lett., 2017, 19, 2398; D. L. Priebbenow, L. Barbaro and J. B. Baell, Org. Biomol. Chem., 2016, 14, 9622; Z. J. Wang, M. Kanai and Y. Kuninobu, Org. Lett., 2017, 19, 2398.

5 X. Wang, Y. X. Ye, S. N. Zhang, J. J. Feng, Y. Xu, Y. Zhang and J. B. Wang, J. Am. Chem. Soc., 2011, 133, 16410; G. J. Ji, X. Wang, S. N. Zhang, Y. Xu, Y. X. Ye, M. Li, Y. Zhang and J. B. Wang, Chem. Commun., 2014, 50, 4361.

6 G. F. Koser, A. G. Relenyi, A. N. Kalos, L. Rebrovic and R. H. Wettbach, J. Org. Chem., 1982, 47, 2487; G. F. Koser and R. H. Wettach, J. Org. Chem., 1977, 42, 1476.

7 K. Kiyokawa, S. Yahata, T. Kojima and S. Minakata, Org. Lett., 2014, 16, 4646.

8 A. Utaka, L. N. Cavalcanti and L. F. Silva, Chem. Commun., 2014, 50, 3810.

9 Y. P. Fan, W. Wan, G. B. Ma, W. Gao, H. Z. Jiang, S. Z. Zhu and J. Hao, Chem. Commun., 2014, 50, 5733.

10 H. Y. Niu, C. Xia, C. R. Qu, Q. Zhang, Y. Jiang, Y. Z. Mao, Z. Y. Lia and H. M. Guo, Org. Biomol. Chem., 2011, 9, 5039.

11 W. B. Liu, P. Zhou, C. Chen, Q. Zhang and Z. B. Zhu, Org. Biomol. Chem., 2013, 11, 542; W. B. Liu, C. Chen and Q. Zhang, Org. Biomol. Chem., 2011, 9, 6484.

12 B. T. Cho, W. K. Yang and O. K. Choi, J. Chem. Soc., Perkin Trans. 1, 2001, 1204; J. Vantikommu, S. Palle, P. S. Reddy, V. Ramanatham, M. Khagga and V. R. Pallapothula, Eur. J. Med. Chem., 2010, 45, 5044. 
13 R. S. Varma, K. P. Naicker and D. Kumar, J. Mol. Catal. A: Chem., 1999, 149, 153; R. S. Varma and D. Kumar, Catal. Lett., 1998, 53, 225.

14 K. C. Nicolaou, T. Montagnon, T. Ulven, P. S. Baran, Y. L. Zhong and F. Sarabia, J. Am. Chem. Soc., 2002, 124, 5718; R. S. Varma, D. Kumar and P. J. Liesen, J. Chem. Soc., Perkin Trans. 1, 1998, 4093.
15 B. Basdevant and C. Y. Legault, J. Org. Chem., 2015, 80, 6897; A. A. Guilbault and C. Y. Legault, ACS Catal., 2012, 2, 219.

16 J. P. Wan, Y. F. Lin, X. J. Cao, Y. Y. Liu and L. Wei, Chem. Commun., 2016, 52, 1270.

17 J. Deng and J. Luo, Tetrahedron, 2013, 69, 5937.

18 D. Zhang-Negrerie and Y. Du, Chem.-Eur. J., 2015, 21, 5193. 